\title{
Replies to Glick, Hanks, and Magidor
}

Analysis Reviews (forthcoming)

Trenton Merricks

\section{Reply to Glick}

\section{I}

Here is how Ephraim Glick puts the first premise of my argument for the existence of propositions:

(M1) $\exists x x \exists y(\sim(y<x x) \& \square(x x$ are true $\rightarrow y$ is true $))$

Glick's (M1) is a better-a more precise-way of stating that premise than is the way I usually state it, which is: 'there are modally valid arguments'.

Glick claims that I need an argument for there being modally valid arguments (i.e., for (M1)). He then presents an argument for there being modally valid arguments. He then points out that that argument can be blocked if some more familiar arguments for propositions can be blocked. He then concludes: 'if the nominalist has a decent strategy for responding to these more familiar arguments for the existence of propositions, then she already has a decent strategy for responding to Merricks.'

\footnotetext{
${ }^{1}$ But (M1) is not perfect. Let the xs be electrons, and assume that an electron cannot have a truth-value. Then this conditional will be (vacuously) true: $\square(\mathrm{xx}$ are true $\rightarrow \mathrm{y}$ is true), and some electrons plus anything that is not one of those electrons will deliver (M1). Let us not worry about this; instead, in what follows (esp. §III), let us just assume that (M1)’s xs must have truth-values.
} 
I do not give any argument for the conclusion that there are modally valid arguments. (So I do not give any such argument that can be blocked in the way that more familiar arguments can be blocked.) And I do not agree with Glick's claim that I need such an argument. For all arguments have premises. So you have to start somewhere. Your starting place need not be absolutely indubitable. (Sorry, Descartes.) And my starting place is that there are modally valid arguments. Thus Propositions opens with:

Let an argument be modally valid just in case, necessarily, if its premises are true, then its conclusion is true. This book begins with the assumption that some arguments are modally valid. (xiii)

And Chapter 1 begins:

An argument is modally valid just in case, necessarily, if its premises are true, then its conclusion is true. This book's starting point is that there are some modally valid arguments. (1)

You have to start somewhere. But not every starting place is reasonable. So I say why I think that it is reasonable for me to start with the claim that there are modally valid arguments. First, I point out that many philosophers have asserted, in one way or another, that some arguments are modally valid (1-4, 61-4). ${ }^{2}$ And, second, I point out that it seems obvious, at least to me, that this or that argument is modally valid (3). But none of this is supposed to be an argument for the conclusion that there are modally valid arguments. For, again, that some arguments are modally valid is my starting point. (Cf. Merricks, 2016a, 490-3.)

\section{II}

\footnotetext{
${ }^{2}$ Unless otherwise noted, all page references are to Propositions.
} 
I think that it is reasonable to start with the claim that some arguments are modally valid, and I think this because of the two points noted above. But Glick objects that I, in particular, should deny that those points make that claim a reasonable starting point. For he says:

Merricks himself accepts...nihilism about composite objects. Despite the wisdom of the past and of the crowd, Merricks would say that if the realist about tables wants to take metaphysics seriously, she needs an argument that tables exist. It is not enough for her to say that it's obvious and that nearly everyone believes it. So it seems to me that we certainly deserve an argument for the substantially more theoretical claim that there are premises and conclusions of modally valid arguments.

But I think that you may - and even should — start with the view that there are tables. After all, the view that tables exist is venerable and widespread. And your starting with this view is even more reasonable if it seems obvious to you (as I am given to understand that it does to some) that there are tables. More generally, I think that it is reasonable in philosophical inquiry to start with what is widely endorsed and what seems obvious to you. (It would be perverse to start with what everyone rejects and what seems to you to be mistaken!)

Of course, where you may start is not always where you should end. For example, suppose you start with the claim that there are tables. Then you should conclude that tables cause nothing that is not already caused by their parts working in concert. But then you should conclude that sense perception justifies neither you nor the crowd in believing that tables exist. So you should conclude that the question of whether tables exist is one to be settled by philosophical argument (as opposed to by what you and the crowd think that you see, etc.). But the weight of philosophical argument supports the conclusion that 
there are no tables. At least, all this is what I say - see Merricks, 2001, esp. Chs. 2-3 and Merricks, 2016b.

Glick raises a number of objections to an argument for (M1) to which I shall not reply, since I do not defend that argument. But one comment Glick makes about (M1) could be turned into an objection to which I should reply. Glick says:

A related strategy for responding to (M1) is to appeal to some notion of fundamentality and to say that what really matters to ontology is not what exists, but what is fundamental.

So suppose that (M1) - that is, the claim that there are modally valid arguments delivers the result that there are propositions. The objection here is that this result does not matter. The result that does (or would) matter is the result that propositions are fundamental. But (M1) does not deliver that result.

I reply that a variety of ontological claims matter (cf. Merricks, 2013). Some of those claims concern fundamentality, but some concern existence. Indeed, some claims about existence are even more interesting than the correlative claims about fundamentality. For example, suppose that we could show that tables do not exist. That would be much more interesting (in my opinion) than showing that tables are not fundamental.

At any rate, Propositions defends the conclusion that propositions exist (and have various features). I think that this conclusion is interesting and matters. The book does not defend the claim that propositions are fundamental, a claim that is also interesting and also matters. But the book does defend the view that propositions are simple, that is, have no constituents (205-7). Perhaps that view suggests that propositions are fundamental. 


\section{III}

\section{Glick says:}

But it's still not clear what the objection is to the truth-at analysis of modal validity. The proponent of the latter has two key ideas: Modal talk can be analyzed in terms of quantification over worlds, and truth can be understood as either truth-in-a-world or truth-at-a-world.

I disagree with both of these key ideas. I deny that modality can be analyzed in terms of possible worlds. And I understand truth in a world and truth at a world in terms of (among other things) truth, and not the other way around.

Let me explain. I think that a possible world just is a proposition that is both appropriately maximal and also possibly true (see esp. 110-17). A possible world's being actual just is that world's being true. An entity's being true in a world w is analyzed as: necessarily, if w were actual (=true), then that entity would be true (14). An entity's being true at a possible world $\mathrm{w}$ is analyzed as: that entity actually has certain truth conditions and, necessarily, if w were actual (=true) then those truth conditions would be satisfied (14).

For example, 'Socrates is mortal' is true at all worlds that are such that, if they were actual, then Socrates would be mortal. Let us abbreviate this as: 'Socrates is mortal' is true at all worlds in which Socrates is mortal. Given this understanding of truth at a possible world, I claim that an argument's conclusion being true at all possible worlds at which its premises are true is not sufficient for that argument to be modally valid. I defend this claim in the book $(14-17 ; 115)$. And here I will defend this claim by building on some points Glick himself makes. 
Recall Glick's way of putting my assumption that there are modally valid arguments:

(M1) $\exists \mathrm{xx} \exists \mathrm{y}(\sim(\mathrm{y}<\mathrm{xx}) \& \square(\mathrm{xx}$ are true $\rightarrow \mathrm{y}$ is true $))$

Much of Sections 3 and 4 of Glick's contribution to this symposium emphasizes that there is no non-controversial way to get to (M1) from:

(a) Necessarily, if all men are mortal and Socrates is a man, then Socrates is mortal.

I agree with Glick that (M1) does not follow from (a) without adding controversial premises. This is because the 'modal connection' endorsed by (a) involving Socrates and male humans and death is silent on whether there are some xs such that their truth necessitates the truth of some $y$.

Suppose Glick is right that (M1) does not follow from (a) without adding controversial premises. Then (M1) does not follow from (a) plus the following uncontroversial premise about truth conditions: 'All men are mortal' is true if and only if all men are mortal; 'Socrates is a man is true' if and only if Socrates is a man; and 'Socrates is mortal' is true if and only if Socrates is mortal.

(M1) does not follow from (a) plus this uncontroversial premise about truth conditions. But (a) plus this uncontroversial premise about truth conditions does get us the result that 'Socrates is mortal' is true at all possible worlds at which 'All men are mortal' and 'Socrates is a man' is true. Therefore, more is required for there to be modally valid arguments - that is, for (M1) to be true - than for there to be an argument such that its conclusion is true at all possible worlds at which its premises are true. This is the objection to the 'truth-at analysis of modal validity'. 
(The uncontroversial premise implies both that 'Socrates is mortal' is true at all worlds in which Socrates is mortal and also that 'All men are mortal' and 'Socrates is a man' are true at all worlds in which all men are mortal and Socrates is a man. And Glick's (a) implies that all worlds in which all men are mortal and Socrates is a man are worlds in which Socrates is mortal. This is why (a) plus the uncontroversial premise about truth conditions implies that 'Socrates is mortal' is true at all possible worlds at which 'All men are mortal' and 'Socrates is a man' is true.)

I say:

[L]et $\mathrm{S}$ be a sentence whose truth conditions are satisfied in all possible worlds. Then $\mathrm{S}$ is true at all possible worlds. S could have had different truth conditions. So $\mathrm{S}$ could have been false. So the claim that necessary truth is truth at all possible worlds yields the result that some necessary truths could have been false. I think that result is mistaken. So I deny that necessary truth is truth at all possible worlds. (18)

Glick responds: 'One of the truth-at theorist's points is that there is a danger of equivocation when we talk about possible truth or falsity', where the equivocation in question is between claims about what is true or false at possible worlds and claims about what is true or false in possible worlds. And Glick's 'truth-at theorist' objects that the passage just quoted trades on just such an equivocation when it says: 'S could have been false. $^{3}$

My reply begins by pointing out that modality outstrips necessary truth (falsity) and possible truth (falsity). For example, I am an American, but I could have been a Canadian instead. The claim that I could have been a Canadian is not in danger of being

\footnotetext{
${ }^{3}$ Note that Glick's truth-at theorists cannot give an analysis of being a possible world that invokes possible (or necessary) truth (or falsity), lest, by their lights, that analysis threaten to be ambiguous, and its disambiguations (which they take to be in terms of truth at or truth in possible worlds) circular. So what is a possible world, according to them?
} 
equivocal in the relevant way. This is because the charge that a claim equivocates between truth (falsity) in a world and truth (falsity) at a world is coherent only when that claim is about necessary truth (falsity) or possible truth (falsity).

Again, the claim that I could have been a Canadian is not in danger of being equivocal in the relevant way. But then I say that neither is the claim - in the passage quoted above - that sentence $\mathrm{S}$ could have been false. For I say that the modal notions invoked are the same in both cases. Likewise, the claim that, necessarily, if something is a dog, then it is an animal is not in danger of being thus equivocal. But then neither is the claim that, necessarily, if the premises are true, then the conclusion is true. Again, the modal notions invoked are the same.

\section{Reply to Hanks}

\section{I}

Peter Hanks says:

.... what could it be to [believe] a simple, unstructured proposition? Again, if a proposition has no constituents then it can't be a matter of performing an operation on those constituents. Nor can it be a matter of taking the proposition to be true, since that leads to a regress... the act of [believing] an unstructured proposition looks as though it has to be taken as primitive and unanalyzable.

Suppose you think that if propositions have constituents, then believing the proposition that Russell is a philosopher is analyzed as performing an operation on its constituents and, in particular, as predicating being a philosopher of Russell. Then you should also think that if propositions do not have constituents, believing the proposition that Russell is a philosopher is analyzed as predicating being a philosopher of Russell. 
To see why I say this, consider that the proposition that Russell is a philosopher represents Russell as being a philosopher. This is why predicating being a philosopher of Russell seems to be relevant to believing that proposition. And this seeming relevance is not diminished if propositions lack constituents. Or look at it this way. No one would say that what it is to believe the proposition that represents Russell as not being a philosopher is to predicate being a philosopher of Russell. No one would say this even if that proposition has (among other things) Russell and being a philosopher as constituents.

My point here is not that we should endorse the predication-based account of believing a proposition. Rather, my point here is merely that that account is not undermined by the claim that propositions lack constituents. And let me add-for a reason that will become apparent below - that that account is not undermined by the claim that there is no explanation of how a proposition manages to represent things as being a certain way; in other words, that account is not undermined by the claim that each proposition primitively represents things as being a certain way.

\section{II}

One sort of functionalism says that what it is to represent things as being a certain way is to play a certain causal role. (You could call this 'content functionalism'.) This sort of functionalism offers a proposition-free account of what it is for a mental state to represent things as being a certain way; so this sort of functionalism seems to be inconsistent with my claim that an agent represents things as being a certain way in virtue of standing in the believing relation to a proposition that represents things as being that 
way. Moreover, propositions are paradigmatic abstracta (192-3); so propositions do not play any causal roles; so this sort of functionalism is inconsistent with my claim that propositions represent things as being a certain way.

A second sort of functionalism offers an informative account of the believing relation. This second sort says that what it is for an agent to stand in the believing relation (as opposed to, say, the doubting relation) to a particular proposition is for that agent to have a mental state that plays a certain causal role. (You could call this 'attitude mode functionalism'.) This second sort of functionalism is consistent with my claim that an agent represents things as being a certain way in virtue of standing in the (thus analyzed) believing relation to a proposition that represents things as being that way. Moreover, this second sort of functionalism is consistent with my claim that propositions represent things as being a certain way, and do so primitively.

Hanks claims that my view that propositions primitively represent things as being a certain way leads to the result that the believing relation is primitive. But I deny Hanks's claim. For my view is consistent with the functionalist account of the believing relation just considered. And my view is also consistent with the predication-based account considered in Section I. So my view is consistent with there being an informative account of the believing relation.

\section{Hanks says:}

Functionalism offers an informative, constitutive account of what it is to bear the belief relation to a proposition. That account explains how the mental state that is a belief that $p$ has the representational features that it has, and it does so without mentioning the proposition that $p$.

I think Hanks here conflates the aforementioned two sorts of functionalism. He begins with the sort of functionalism that offers an account of the believing relation that holds 
between an agent and a proposition. But then, with the very next sentence, he takes

functionalism to offer a proposition-free account of what it is for a mental state to

represent things as being a certain way.

Hanks continues:

But that's what any informative, constitutive account of the belief relation will do. Such an account will have the form: $x$ believes that $p$ iff such-and-such, where 'such-and-such' does not include primitive, irreducible relations between subjects and propositions. The account explains away these relations in terms of other facts or conditions or relations borne by the subject. But those facts or conditions or relations will provide an account of what it is for the subject to be in a mental state that represents things as being a certain way. And that implies that these mental states are fundamental bearers of representation that do not derive their representational features from propositions.

Here too Hanks seems to conflate an informative account of the believing relation, which relates an agent to a proposition, with a proposition-free account of what it is for a mental state to represent things as being a certain way.

\section{III}

Each proposition is a necessarily existing entity that essentially represents things as being a certain way. That is my account of the nature of propositions (191-4). I point out that my account has the result that each proposition primitively represents things as being a certain way (194-6). But-despite what Hanks says - I do not point this out as a way to support the claim that each proposition primitively represents things as being a certain way. Rather, I point this out to support my account of the nature of propositions. ${ }^{4}$

\footnotetext{
${ }^{4}$ There is, however, an interesting argument that starts with a claim about the nature of propositions and ends with the conclusion that propositions primitively represent things as being a certain way. See Pautz (2016) and Merricks (2016a, 499-501).
} 
The arguments in the book should lead us to conclude that propositions primitively represent things as being a certain way. Thus the fact that my account of the nature of proposition implies that propositions primitively represent things as being a certain way counts in its favor. More generally, I endorse my account of the nature of propositions because, despite its evident simplicity, it implies that propositions have all the features and play all the roles that - so I argue throughout the book-propositions have and play $(191-7) .^{5}$

In the book, I argue that an acceptable explanation of how a proposition manages to represent things as being a certain way may not rely on the cognitive activity of agents (135-9; and below). Moreover, so I argue, there is no successful explanation in terms of a proposition's structure and constituents $(94-8 ; 133-156)$. But then I have no idea-not an inkling - of how such an explanation would even go. This is why I said that the arguments in the book should lead us to conclude that propositions primitively represent things as being a certain way (196).

Hanks objects:

But even if I also had no inkling of how the explanation would go I'm not sure I would share Merricks's pessimism about finding such an explanation. If there were no significant costs to going primitive about the representational powers of propositions then such pessimism might be justified. But there are significant costs to giving up on explaining how propositions are representational. That is what I tried to show earlier with the point about creeping primitivism.

But - in light of Sections I and II above-I reply that 'going primitive' about representation does not usher in 'creeping primitivism'.

\footnotetext{
${ }^{5}$ Contra Hanks, I do not take 'occurring in modally valid arguments [to be] the most important or most central role for propositions'.
} 
Hanks also objects that I fail to appreciate some potential explanations of how a proposition manages to represent things as being a certain way, citing his recent (and excellent) book, Propositional Content. A proposition's truth conditions are intimately related to how it represents things as being (cf. 19-20). So let us consider Hanks's explanation of a how a proposition manages to have its truth conditions.

Hanks says that token 'acts of predication... are the primary and metaphysically basic bearers of truth conditions' $(2015,66)$; 'Propositions are types' of these tokens $(2015,73)$; and 'the possession of truth conditions by a type is constituted [and so explained] by the possession of truth conditions by actual or possible tokens of that type'. $(2015,75)$. Thus Hanks explains a proposition's truth conditions in terms of the truth conditions of certain actions, such as an agent's predicating a property of an object.

I do not think that Hanks's explanation is successful. To begin to see why, suppose, for reductio, that human cognitive activity plays a role in explaining how propositions manage to have their respective truth conditions. Human cognitive activity occurs contingently. This implies - given our supposition for reductio-that either propositions exist contingently or, instead, propositions have their respective truth conditions contingently (see 135-9).

But each proposition exists necessarily and has its truth conditions essentially (see, e.g., 4-22). So what we supposed for reductio is false. That is, it is false that human cognitive activity plays a role in explaining how a proposition manages to have its truth conditions. I think that this implies that it is false that token human cognitive acts explain a proposition's truth conditions. And I think that this implies that Hanks's explanation of how a proposition manages to have its truth conditions is false. 
In Propositional Content, Hanks says:

...types of acts of predication inherit their truth conditions from their actual or possible tokens. A type of act of predication need not have any actual tokens in order for it to have truth conditions. Even if no one ever has or ever will predicate eloquence of Clinton, this type of act of predication is true iff Clinton is eloquent because if there were any tokens of this type, those tokens would be true iff Clinton is eloquent. The fact that types of acts of predication have truth conditions is constituted by the possession of those truth conditions by its actual or possible tokens. $(2015,76)$

These remarks suggest that a type of act of predication can inherit its truth conditions from merely possible tokens of that type. This suggestion, if correct, would give Hanks the resources to deny that his view implies either that propositions exist contingently or that propositions have their truth conditions contingently. For Hanks could deny that it is contingent that there are merely possible tokens of the relevant type.

But I think that only existing entities have properties. So only existing token acts of predication have truth conditions. I do not think that any merely possible token acts of predication exist. (To say that a token of a given type is 'merely possible' is-according to me - to deny that such a token exists, while affirming that there could have been such a token.) So I deny that a cognitive act type could inherit its truth conditions from a merely possible cognitive act token. Thus I still maintain that Hanks's proffered explanation of a proposition's truth conditions unacceptably implies that either propositions exist contingently or have their truth conditions contingently. 
Hanks suggests that propositions might not be the fundamental bearers of truth conditions or representational features, but might instead 'play a classificatory role'. He then says:

This classificatory role for propositions is in tension with the traditional idea that propositions are the original or primary bearers of representation and truth conditions. You have to make a choice here. Either beliefs are fundamental bearers of representation and propositions serve a classificatory role, or beliefs are non-fundamental bearers of representation and propositions serve as a source of representation and truth conditions. Merricks chooses the second, more traditional option.

I would not put it this way. That is, I would not say that I recognized this choice, and decided to choose the more traditional option. I would say, instead, that I present arguments for the conclusion that propositions (exist and) are the fundamental bearers of representational properties and truth conditions (18-29). So-unless those arguments fail-nothing here is a matter of choice.

\section{Reply to Magidor}

Let an ideal reasoner be an agent who always sees whether an argument's conclusion follows from its premises in virtue of form (36-9; 53-6). ${ }^{6} \mathrm{I}$ assume that it is never rational to: accept some premises, see that a conclusion follows from those premises in virtue of form, and reject that conclusion. So I conclude that if an ideal reasoner rationally both accepts the premises of an argument and also rejects its

\footnotetext{
${ }^{6}$ That is, an ideal reasoner always sees this whenever he or she understands the premises and conclusion well enough to grasp their form (if any). In the examples alluded to below, assume that the ideal reasoner does understand the relevant premises and conclusions well enough to grasp their form (if any).
} 
conclusion, then that conclusion does not follow from those premises in virtue of form. In other words, that argument is not logically valid.

Let an argument be 'constituted' by propositions just in case its premises and conclusion are propositions. In the book, I present some single-premise arguments that are constituted by propositions. Moreover, for each of those arguments, the premise is the same proposition as the conclusion. I then argue that, for each of those arguments, an ideal reasoner can rationally both accept its sole premise and also reject its conclusion. So I conclude that those particular single-premise arguments - each of which has one and the same proposition as both its premise and conclusion - are not logically valid.

I think that if any argument constituted by propositions were logically valid, then every argument whose sole premise is the same proposition as its conclusion would be logically valid. But there are some single-premise arguments - each of which has one and the same proposition as both its premise and conclusion - that are not logically valid. (An example will be presented below.) So I conclude that no argument constituted by propositions is logically valid.

I have not here defended my conclusion that no argument constituted by propositions is logically valid. Instead, I have merely described the strategy behind one strand of that defense. (For the full defense, see 34-60.) But this is enough to set up my discussion of:

\footnotetext{
${ }^{7}$ Another strand of that defense turns on the claim that an ideal reasoner who understands the premises and conclusion of a logically valid argument can always know a priori of that argument that its conclusion is a consequence of its premises. The 'always' here is meant to be imply, among other things, that the ideal reasoner can know this a priori regardless of the guise under which the argument itself is presented. (See 36-37, 42-44.) Magidor criticizes this strand of argument by criticizing a thesis she calls 'IR3'. But this strand of argument does not presuppose IR3, not as Magidor interprets (and criticizes) IR3.
} 
IR2: If an ideal reasoner believes the premises of a logically valid argument, then she does not reject the conclusion of that argument.

Ofra Magidor says that I endorse IR2. But I do not. For IR2 seems to involve a reasoner who is ideal with regard to rationality. (My ideal reasoner is ideal only with regard to seeing what follows in virtue of form. ${ }^{8}$ ) But I did assume above that it is never rational to accept some premises, see that a conclusion follows from those premises in virtue of form, and also reject that conclusion. So let us ask whether Magidor's potential counterexamples to IR2 threaten my above assumption.

Her potential counterexamples involve agents who accept a ham-fisted dialetheism and agents who have certain confused views on vagueness. Suppose that it is never rational for even these agents to accept the premises of an argument, see that that argument's conclusion follows from those premises in virtue of form, and reject that conclusion. Then these agents do not deliver counterexamples to my above assumption that it is never rational to accept some premises, see that a conclusion follows from those premises in virtue of form, and also reject that conclusion.

So let us suppose - if only for the sake of argument - that it is rational for hamfisted dialetheists or those with certain confused views on vagueness to accept some premises and reject a conclusion, all the while seeing that that conclusion follows from those premises in virtue of form. Then my above assumption is false. But I do not think we should completely discard that assumption. Rather, we should qualify it.

In fact, I already qualified that assumption in Propositions:

\footnotetext{
${ }^{8}$ I should have been more explicit about the relevant idealization in Propositions. Had I been more explicit, Magidor might not have taken me to endorse IR2, and might not have said: 'I have general reservations about... appeal to 'ideal reasoners', especially as there is no clear criterion for which dimensions of idealisations we ought to focus on.'
} 
One moral of the 'paradox of the preface' is that even an ideal reasoner might accept the many premises of a logically valid argument whose conclusion is the conjunction of those premises, but rationally reject that conclusion, since she figures that she is probably mistaken about the truth of at least one of the many premises (Beall and Restall, 2006, 16-17). In what follows, I shall consider only very short arguments. Moreover, it should be uncontroversial that, for each of those arguments, an ideal reasoner who accepts its premises, could not-if that argument were logically valid - rationally reject its conclusion. (38n2)

Suppose that the sentence 'Smith is a doctor' and the sentence 'Smith is a physician' express the same proposition. Let that Smith is a doctor/physician be that proposition. Now consider an argument that has that proposition as its premise and also as its conclusion. I argue that there can be a situation in which an ideal reasoner can rationally accept (believe) the premise of that argument - namely, the proposition that Smith is a doctor/physician-and also reject (believe to be false) the conclusion of that argument—namely, the proposition that Smith is a doctor/physician.

The situation I have in mind does not require the ideal reasoner to be a ham-fisted dialetheist. Nor does it turn on Smith's being a 'borderline doctor' and the ideal reasoner's having confused views on vagueness. Nor does it suggest that our singlepremise argument is relevantly like the paradox of the preface. Instead, that situation involves the ideal reasoner's accepting that Smith is a doctor/physician under a guise associated with 'Smith is a doctor' and rejecting that same proposition under a guise associated with 'Smith is a physician'.

I defend the conclusion - and this does need to be defended - that all of this shows that the argument that has that Smith is a doctor/physician as its premise and also as its conclusion is not logically valid. More generally, I defend the conclusion that it is

\footnotetext{
${ }^{9}$ See pages 36-9 and especially pages 53-6 for why it is appropriate to take our reasoner to be ideal only with respect to recognizing what follows in virtue of form, and so not ideal with respect to recognizing synonymy.
} 
false that logically valid arguments are constituted by propositions in and of themselves and so regardless of which sentences express them. Rather, so I argue, logically valid arguments are always constituted by proposition-expressing sentences. (See 34-60.)

Magidor says that I defend this argument: propositions are not structured; only structured propositions have logical form; therefore, propositions do not constitute logically valid arguments. But I do not defend that argument; on the contrary, I explicitly say: 'denying that propositions are structured...does not all by itself deliver the conclusion that propositions do not constitute logically valid arguments' (46). I did say, however, that unless propositions are structured, they cannot constitute arguments that are valid by the lights of predicate logic in particular (46).

But I should not have said that. Instead, I should have said only that the most natural way to extend the models for predicate logic to propositions requires structured propositions (see 45-6). For I agree with Magidor that there are coherent views according to which non-structured propositions have logical form, and so constitute logically valid arguments even by the lights of predicate logic. In fact, the book mentions the very sort of view Magidor develops along these lines, a view that both she and I associate with George Bealer (1998) (149-50).

\section{II}

\section{Magidor says:}

Since Merricks takes a singular proposition about an entity to be essentially about that entity, it follows that there are worlds relative to which the proposition stands in the aboutness relation to the individual in question even though that individual does not exist. But this is in direct contradiction to serious actualism. 
But I deny that a proposition's being about an entity implies that that proposition stands in the aboutness relation-or any other relation - to that entity.

Let me explain. The proposition that Lincoln debated a senator represents Lincoln as debating a senator. Because that proposition represents Lincoln-as opposed to someone else-as doing something, I say that that proposition is 'about Lincoln'. To say that a proposition is about Lincoln is, for me, only to partially describe how that proposition represents things as being. This partial description of that proposition's representational features does not imply that that proposition stands in the aboutness relation — or any other relation — to Lincoln. (See 157-62; 180-9.)

I endorse the following sentence: 'The proposition that Lincoln debated a senator is about Lincoln'. But I also deny that the proposition that Lincoln debated a senator stands in the aboutness relation to Lincoln. Magidor objects:

The problem with this proposal is that, for anyone who doesn't have general qualms about predicates expressing properties (and I take it Merricks does not have such general qualms), it is hard to see how a sentence of the form ' $\mathrm{R} p a$ ' can be true without $p$ standing in the relation $R$ to $a$.

I endorse the sentence 'The proposition that Lincoln debated a senator is about Lincoln' only because I do not take it to predicate a relation's holding between that proposition and something else. Instead, I take that sentence to predicate a non-relational feature of that proposition, namely, the feature of representing things as, in some way or other, involving Lincoln. So I suppose that sentence has the form ' $\mathrm{F} p$ ', as opposed to ' $\mathrm{R} p a$ '. ${ }^{10}$

\footnotetext{
${ }^{10}$ Moreover, I deny that a sentence of the form ' $\mathrm{R} p a$ ' can be true only if $p$ stands in the relation $\mathrm{R}$ to $a$. For example, suppose a fairly sparse theory of properties is true (cf. Merricks, 2003). In particular, suppose that there is no such relation as being redder-rounder-and-more-rubbery than. Suppose further that the relational predicate 'is clown-nosier than' means: is redder than and is rounder than and is more rubbery than. I do not think that these suppositions - all by themselves - imply that the following sentence cannot
} 
I tell the following story:

While Lincoln is alive - and so while Lincoln exists - [a] journalist says: 'Lincoln debated a senator'... Our journalist keeps repeating, over and over, 'Lincoln debated a senator'. (Don't ask.) As he repeats this, his intentions to assert that Lincoln debated a senator remain the same. And each repeated utterance of 'Lincoln debated a senator' is just what it appears to be: A repeated utterance of the same sentence. And whatever relevant causal-historical chains link the word 'Lincoln' to Lincoln are maintained from utterance to utterance. And there is no change, during these repeated utterances, in any semantic laws that regulate how meaning supervenes on use. And there is no significant change in the use of 'Lincoln', 'debated', or 'senator'. And so on.

Given all this, it seems obvious that our journalist's repeated utterances of 'Lincoln debated a senator' remain unchanged in how they represent things as being. A sentence represents things as being a certain way in virtue of expressing a proposition that represents things as being that way $(\mathrm{Ch} .1, \S \mathrm{V})$. So the journalist keeps expressing the same proposition.

... But let us now add that after the journalist began repeating 'Lincoln debated a senator' - but before he stops - Lincoln is shot and dies. For the reasons noted above, the journalist is still - after Lincoln has died - expressing [the same] proposition about Lincoln... And this is so even if a dead Lincoln no longer exists. (172)

Magidor says this about the above story:

Merricks assumes that since the journalist has not intended to change the meaning of what she is uttering, the post-shooting utterances must also express the same singular proposition (albeit one that is now about an entity that does not exist).

But I do not assume that an agent's failing to intend to change the meaning of what she is uttering is sufficient for that agent's utterances to continue to express the same proposition. (If I had assumed this, the above story would have been shorter.) I also agree with Magidor's objection to that assumption:

I point at a (real) table, and repeatedly utter the sentence 'That is a table', thinking that I am referring to the same table all along. But... if unbeknownst to me the table is replaced between utterances with a different table, my post-replacement utterances express a different proposition.

be true (in a particular context of use): 'That clown's nose is clown-nosier than that brick of coal.' If I am correct, then it is false that a sentence of the form 'Rpa' can be true only if $p$ stands in the relation $\mathrm{R}$ to $a$. 
Here is another story. A journalist pointed at the living Lincoln and uttered: 'That debated a senator'. She thereby expressed the (true) proposition that Lincoln debated a senator. But then Lincoln ceased to exist and was replaced by a corpse (with no debating experience to speak of). The journalist then pointed at the corpse and uttered: 'That debated a senator'. I think that the journalist then expressed a new (false) proposition, one about the corpse and not about Lincoln. This is so even if she did not intend for her utterances to express different propositions.

I give an argument involving 'Noman', which I take to be a name that enables us to express singular propositions about the individual who would have resulted had sperm $\mathrm{S}$ and egg E united. (S and E never unite.) Part of that argument involves defending the claim that 'Noman' is not just short-hand for this description: the individual who would have developed from sperm S and egg E. Magidor offers no objection to my defense of that claim. ${ }^{11}$

But she does object to my following up that claim with: 'More generally, 'Noman' is not a disguised definite description' (177). For she says that this follow-up remark:

....ignores the standard move that defenders of 'names as descriptions' typically make - namely, rigidifying the relevant descriptions. Thus if 'Noman' is instead construed as standing for 'The individual who such that, if actually S and E would have united, then would have formed,' then... the description would either be empty or pick out the same individual 'Noman'.

Let me say something here about how the idea that names are rigidified definite descriptions bears on my argument involving 'Noman'.

\footnotetext{
${ }^{11}$ Or maybe she does. In a footnote Magidor says that the possibility of S and $\mathrm{E}$ forming twins 'would not advance Merricks's argument: arguably, in the twinning world Merricks's description fails to pick out any individual (on pain of failure of uniqueness).' But my argument does not rely on the (confused) idea that the relevant description would pick out an individual if $\mathrm{S}$ and $\mathrm{E}$ had united and resulted in twins. See 176-7.
} 
The whole point of that argument is to oppose (what I call) the received view, that is, the view that singular propositions (exist and) have the individuals that they are directly about as constituents. The defenders of the received view on whom I focus take sentences using names to express singular propositions about the named entity. For example, my targets would say that 'Obama is president' expresses a singular proposition that has Obama himself as a constituent.

With this in mind, suppose that if names are rigidified descriptions, then sentences using names do not express singular propositions (cf. 157-62, esp. 158n1). This supposition implies that it is false that 'Noman does not exist' expresses a singular proposition. So this supposition blocks my 'Noman' argument. But this supposition also undermines the received view. And undermining the received view is the only point of the 'Noman' argument.

Now suppose, instead, that if names are rigidified descriptions, then sentences using names do express singular propositions. Then I would argue that 'Noman does not exist' expresses a singular proposition about Noman, and my argument against the received view would proceed as in the book. Here is an outline: Noman does not exist; only existing entities can be constituents of propositions; so Noman is not a constituent of the singular proposition expressed by 'Noman does not exist'; so the received view is false. (See 173-8 for the full argument.)

Magidor says that Chapter 5's arguments against the received view require 'there to be necessarily existing singular propositions about contingently existing beings'. But neither the argument involving Lincoln nor the argument involving 'Noman' invokes the claim that singular propositions about contingently existing entities exist necessarily. Nor 
does the argument that turns on some false negative existential singular propositions being possibly true (179-80). Nor does the argument that turns on singular propositions about singular propositions (166-9)..$^{12}$

I do, however, give the following argument in Chapter 5: all propositions exist necessarily $(18-19 ; 117)$; so all singular propositions exist necessarily; the received view implies that some singular propositions exist contingently; so the received view is false (162-3). I also give this argument: logically valid sentences express necessarily true propositions; there are logically valid sentences that express singular propositions about contingently existing entities; so some singular propositions about contingently existing entities are necessarily true; necessarily, if a proposition is true, then that proposition exists; so some singular propositions about contingently existing entities exist necessarily; so the received view is false (164-5). ${ }^{13}$

\footnotetext{
12 Magidor does acknowledge this argument in a footnote, and adds: 'The problem with this argument...is that it seems dangerously close to being a version of the truth-teller paradox, and thus it is far from clear that Jane and John's attempted dubbings have succeeded in picking up any propositions at all.' Magidor's reservations concern only the initial version of the argument. They seem irrelevant to the version that gets developed in detail. Here is how I introduce that version:
}

Jane uses 'the first proposition expressed by John on Tuesday' to fix the reference of ' $p$ '. John uses 'the first proposition denied by Jane on Monday' to fix the reference of ' $q$ '. First thing Monday, Jane denies the proposition that John's evidence justifies p. First thing Tuesday, John expresses the proposition that $q$ is about cats. Again, $p$ is a singular proposition about $q$, and $q$ is a singular proposition about $p$. (166)

${ }^{13}$ Magidor attributes this argument to me:

(i) The premises and conclusions of modally valid arguments are propositions. (ii) There are some modally valid arguments with premises or conclusions that are necessarily true or necessarily false. (iii) Necessarily, if a premise (/conclusion) is true (/false) then it exists. Thus propositions exist necessarily.

I never endorse this (bad) argument. In Chapter 2, I do defend an argument whose premises are (ii) and (iii), but its conclusion is: 'Some of the premises and conclusions of modally valid arguments exist necessarily' (19). (Context makes it obvious that relevant 'some' just are those that are necessarily true or necessarily false.) 


\section{III}

I say that propositions represent things as being a certain way, and that this explains their truth conditions (19-20). For example, the proposition that dogs bark represents dogs as barking, which explains why that proposition is true if and only if dogs bark. Magidor claims that because properties do not seem to represent things as being a certain way, the idea that propositions represent things as being a certain way seems to be inconsistent with the idea that propositions are 0-place properties. I have three comments.

First, I agree with Magidor's claim. Indeed, in the book I explicitly reject the thesis that propositions are properties partly because propositions represent things as being a certain way, but properties do not (82-8).

Second, I do not think that Magidor should agree with Magidor's claim. For Magidor seems to find the view that propositions are 0-place properties unproblematic. This view implies that some properties (namely, 0-place properties) have truth conditions. And I do not see why someone who finds it unproblematic to say that some properties have truth conditions would balk at the claim that some properties represent things as being a certain way (cf. 86).

Third, suppose that propositions do not represent things as being a certain way. Then we cannot explain a proposition's truth conditions in terms of how it represents things as being. Once we set aside that explanation, my arguments for the conclusion that each proposition primitively represents things as being a certain way can easily be turned into arguments for the conclusion that each proposition has its truth conditions 
primitively. This latter conclusion undermines structured propositions and propositionsas-sets-of-possible-worlds. (See Ch. 4 and esp. 199-205.)

Magidor wishes that I had either 'provided a more extensive discussion of the issue of fineness of grain, or alternatively...refrained from taking a position on this issue altogether'. My discussion is perhaps a bit more extensive than she indicates (see 19-20; $29-32 ; 40-1 ; 78-81$; and 92-4). But here I want to emphasize only that it is not an option for me to refrain from taking a position on this issue altogether. For example, I must reject the view that propositions are so fine-grained that numerically distinct sentences cannot express the same proposition.

I must reject this view because of my argument for the claim that propositions do not constitute logically valid arguments, discussed in Section I above. For that argument presupposes than an agent can use two sentences to express the same proposition. Those two sentences could be any of the following from the book: 'Jones is a doctor' and 'Jones is a physician'; 'Cicero is an orator' and 'Tully is an orator'; 'Henrietta is gorse' or 'Henrietta is furze'; 'London is pretty' and 'Londres est jolie'; 'I am spilling sugar' and 'that person is spilling sugar' (see esp. 34-60). And of course there are further pairs of sentences that would do the trick (cf. 29-32).

As I stress in the book $(41 ; 57-8)$, you do not have to go along with every one of the above examples to be moved by my argument for the claim that propositions do not constitute logically valid arguments. But you do have to go along with one relevantly similar example. Maybe you will go along with none. Then your view is that propositions 
are so incredibly fine-grained that an agent cannot use numerically distinct sentences to express the same proposition. Since that is your view, you can resist my argument. ${ }^{14}$

Your view is controversial. I would want to know your reasons for it. And I might have some objections to your reasons. Moreover, I think that some of the examples and arguments from Propositions are reasons to deny your view, examples and arguments that are meant to motivate my own claims about how fine-grained propositions are (see 19-20; 29-32; 40-1; 78-81; and 92-4). You might reply — and I would agree-that not every philosopher will share my judgments about examples and endorse all the premises of my arguments. And I might make the same point about your judgments and your premises. And so it goes. ${ }^{15}$

University of Virginia Charlottesville, VA 22904 merricks@virginia.edu

\section{References}

Bealer, G. 1998. Propositions. Mind 107: 1-32.

Beall, J. C. and Restall, G. 2006. Logical Pluralism. Oxford: Oxford University Press.

Hanks, P. 2015. Propositional Content. Oxford: Oxford University Press.

Merricks, T. 2001. Objects and Persons. Oxford: Clarendon Press.

Merricks, T. 2003. Replies to Lowe, Dorr, and Sider. Philosophy and Phenomenological Research 67: 727-744.

Merricks, T. 2013. Three Comments on Writing the Book of the World. Analysis 73: 722736.

\footnotetext{
${ }^{14}$ You can also resist my argument if your view is that propositions are so incredibly fine-grained that an agent cannot use numerically distinct sentences to express the same proposition without thereby recognizing that they express the same proposition. I would respond to this view in exactly the same way that I respond to the view that numerically distinct sentences cannot express the same proposition.

15 Thanks to my colleagues Elizabeth Barnes, Ross Cameron, and Brie Gertler.
} 
Merricks, T. 2015. Propositions. Oxford: Clarendon Press.

Merricks, T. 2016a. Replies to Wang, Speaks, and Pautz. Philosophy and Phenomenological Research 93: 487-505.

Merricks, T. 2016b. Do Ordinary Objects Exist? No. In Current Controversies in Metaphysics, ed. E. Barnes. New York: Routledge.

Pautz, A. 2016. Propositions and Properties. Philosophy and Phenomenological Research 93: 478-486. 